\title{
PENANGANAN SEDIMENTASI PADA PELABUHAN KUALA RAJA KABUPATEN BIREUEN
}

\author{
Cut Rahmawati ${ }^{1}$ \\ ${ }^{1)}$ Program Studi Teknik Sipil, Fakultas Teknik, Universitas Abulyatama \\ Jl. Blang Bintang Lama Km 8,5 Lampoh Keude Aceh Besar, \\ email: profestama7@yahoo.co.id
}

\begin{abstract}
The objective of this study is to provide an alternative design of sediment problems in Kuala Raja Port that causes disadvantages for the local fishermen due to ineffective port utilization. The primary surveys conducted in this study are topographic survey, bathymetry survey, current survey and geological survey. The wind data is obtained from the Malikul Saleh Meteorological Station. Based on the tidal survey, the water surface during the tide water is $1,56 \mathrm{~m}$ above $0.00 \mathrm{~m}$ LWS. The current data shows that the flow rate is low, which is less than $1.5 \mathrm{~m} / \mathrm{sec}$ whereas not interfere ships' movement, because the standard size of ships allowed crossing the shipping lanes is planned less than 50 GT. Based on the correction using $S P M$ nomogram acquired high waves $3.50 \mathrm{~m}$ with wind speed $>20$ knots and the North largest fetch 490.04 miles. Sediment transport on shore of Kuala Raja beach is 46,934.59 m3/year moves from West to East. The hand bore data on the location of the planned jetty obtained SG $=2,648, W c=25.66, \gamma d=1,549, \phi=31.00, c=0.03$. Therefore, the determination of the layout of jetty at Kuala Raja Port is considering the direction of sediment transport, the wave height that occurs, the field data attained and the economic feasibility. Sediment management at the Kuala Raja Port can be done within 2 (two) ways: firstly by increasing the length of the jetty on the left and the right side and, secondly by dredging the navigation channel. The length of the jetty that is needed to expand on the left side is 284 meters long and 127.65 meters long on the right side, in order to avoid the addition of sedimentation volume. The jetty's slope is planned 1: 2 outside the channel and 1: 1 inside the navigation channel. The dredging volume at the port entrance is approximately $39,811.60 \mathrm{~m}^{3}$.
\end{abstract}

Keywords : sedimentation, gredging, port, jetty

Abstrak: Studi ini bertujuan untuk memberikan alternatif desain terhadap persoalan sedimentasi di Pelabuhan Kuala Raja yang telah menyebabkan para nelayan tidak dapat memanfaatkan pelabuhan untuk mencari nafkah. Survei primer yang dilakukan adalah survei topografi, survei batchimetri, survei arus dan survei geologi. Berdasarkan survei pasang surut, beda muka air pasang surut sebesar $1.56 \mathrm{~m}$ di atas posisi $0.00 \mathrm{~m}$ LWS. Dari data arus terlihat kecepatan arus sangat kecil, yaitu kurang dari $1.5 \mathrm{~m} /$ detik dimana kondisi ini tidak mengganggu pergerakan (manuver) kapal karena kapal yang melintasi alur pelayaran direncanakan ukurannya kurang dari 50 GT. Berdasarkan koreksi menggunakan nomogram dari SPM diperoleh tinggi gelombang $3.50 \mathrm{~m}$ dengan kecepatan angin $>20$ knot serta fetch terbesar arah Utara sebesar 490,04 Km. Pergerakan sedimen di pantai Kuala Raja sebesar 46.934,59 m3/tahun yang bergerak dari arah Barat ke Timur. Pertimbangan dalam penentuan lay out penambahan jetty pada Pelabuhan Kuala Raja adalah arah sediment transport, tinggi gelombang yang terjadi, data-data lapangan dan pertimbangan kelayakan ekonomis. Penanganan sedimentasi pada Pelabuhan Kuala Raja dapat dilakukan dengan 2 (dua) cara yaitu dengan penambahan panjang jetty pada sisi kiri dan kanan serta pengerukan alur pelayaran. Panjang jetty yang perlu dibangun pada sisi kiri sepanjang 284 meter dan sisi kanan sepanjang 127,65 meter agar tidak terjadi penambahan volume sedimentasi. Sudut kemiringan jetty direncanakan 1:2 pada sisi luar alur dan 1:1 pada sisi alur pelayaran. Volume pengerukan pada jalur masuk kapal ke pelabuhan sebesar $\pm 39,811.60 \mathrm{~m}^{3}$.

Kata kunci : sedimentasi, pengerukan, pelabuhan, jetty 
Penimbunan sedimentasi pada jalur masuk pelabuhan Kuala Raja telah menyebabkan kerugian yang tidak ternilai bagi Pemerintah Daerah Kabupaten Bireuen khususnya nelayan. Nelayan tidak dapat memanfaatkan pelabuhan sebagai pusat distribusi hasil tangkapan ikan dan sebagai tempat sandar boat-boat nelayan.
Akibat lain yang ditimbulkan adalah terbengkalainya infrastruktur pelabuhan yang telah dibangun oleh Pemerintah Daerah Kabupaten Bireuen.

Studi ini bertujuan untuk memberikan alternatif desain terhadap persoalan sedimentasi di Pelabuhan Kuala Raja sehingga pelabuhan dapat dioperasikan kembali.
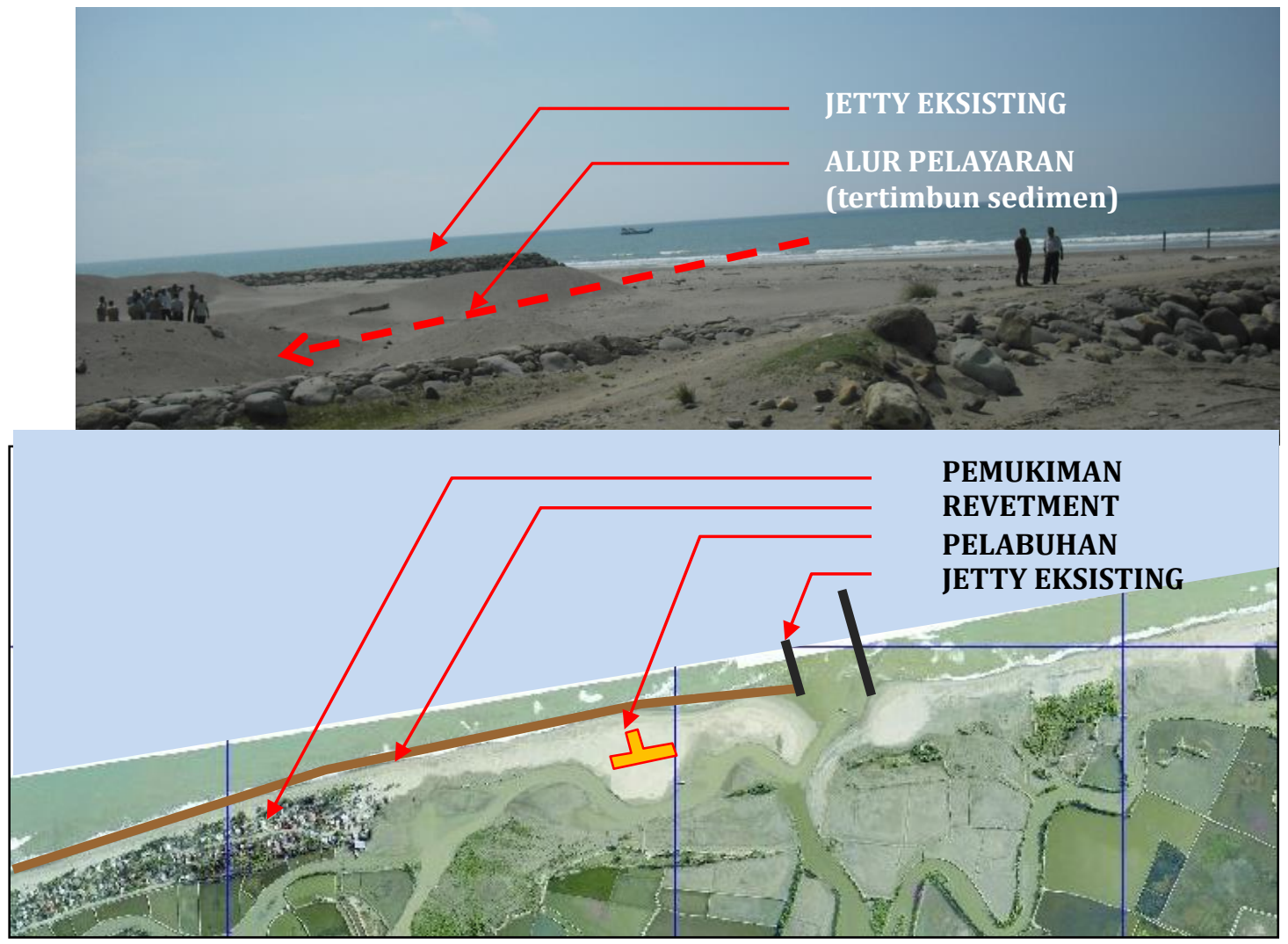

Gambar 1. Kondisi Eksisting Pelabuhan Kuala Raja

\section{KAJIAN PUSTAKA}

\section{Pemetaan Bathimetri dan Topografi}

Peta Bathimetri menunjukan kontur kedalaman dasar laut diukur dari posisi 0.00 LWS. Dengan peta bathimetri dapat diketahui kedalaman dasar laut sehingga dapat disediakan perairan yang aman untuk lalu- lintas kapal dan perencanaan pengerukan dapat dilaksanakan secara tepat.

\section{Data Pasang Surut}

Data ini dipergunakan untuk melengkapi kebutuhan penggambaran peta bathimetri (peta kontur kedalaman laut) dan mengetahui posisi muka air laut absolut terendah dan pola 
pasang surutnya. Posisi muka air laut absolut terendah digunakan sebagai acuan untuk penetapan elevasi kontur tanah dan elevasi seluruh bangunan sehingga kondisi kedalaman perairan dan elevasi posisi kering dari struktur dan wilayah darat dapat ditentukan

\section{Data Arus}

Kegunaan data arus pada studi ini adalah :

- Mengetahui arah pergerakan sedimen

- Menghindari pengaruh tekanan arus berarah tegak lurus kapal (cross current) sehingga kapal dapat bermanuver dengan cepat dan mudah.

\section{Angin}

Untuk mengetahui tinggi gelombang yang terjadi di lokasi studi dibutuhkan data angin karena pembentuk gelombang yang utama di laut adalah angin. Gelombang yang dibangkitkan oleh angin merupakan gelombang yang sangat penting terutama terhadap proses morfologi pantai ataupun perencanaan bangunan pelindung pantai.

\section{Gelombang}

Gelombang merupakan faktor penting di dalam studi ini. Gelombang digunakan untuk studi ketenangan di alur pelayaran dan fasilitas-fasilitas lainnya. Gelombang tersebut akan menimbulkan gaya-gaya yang bekerja pada bangunan pantai dan kapal.

Kecepatan angin yang akan digunakan untuk peramalan gelombang adalah :

$$
U=R_{L} * R_{T} *\left(U_{10}\right)_{L}
$$

Dimana :

RT = Koreksi akibat adanya perbedaan antara temperatur udara dan air

RL $=$ Koreksi terhadap pencatatan angin $\mathrm{di}$ darat

$(\mathrm{U} 10) \mathrm{L}=$ Kecepatan angin pada ketinggian 10 m di atas tanah.

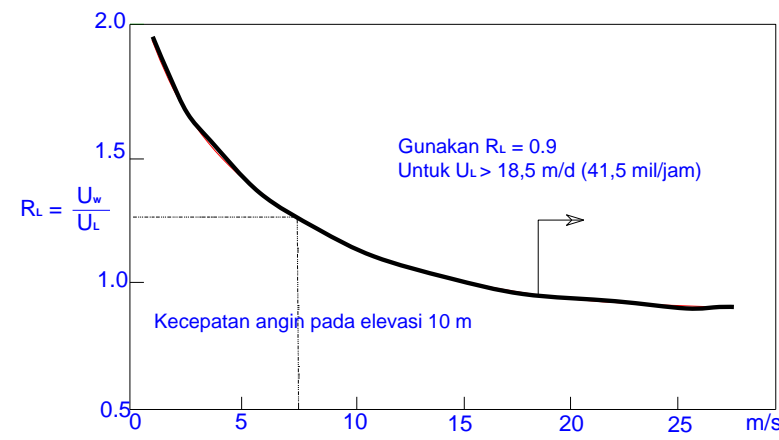

Sumber : CERC, Shore Protection Manual (1984: 3-31)

Gambar 1. Grafik Koreksi Akibat Perbedaan Ketinggian (rl)

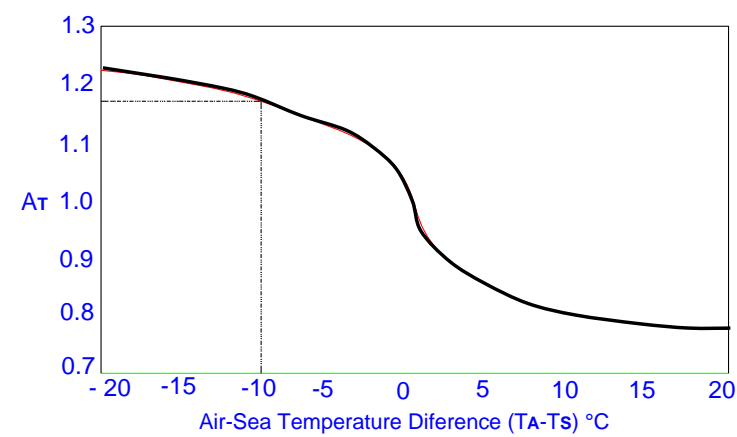

Sumber : CERC, Shore Protection Manual (1984: 3-31)

\section{Gambar 2. Grafik Koreksi Akibat Perbedaan Temperatur (R-r)}

Hasil dari perhitungan kecepatan angin tersebut kemudian dikonversikan menjadi faktor tegangan angin (UA) dengan menggunakan rumus dari CERC, Shore Protection Manual, (1984 : 3-30) yaitu :

$$
U A=0.71 * U^{1.23}
$$

\section{Fetch (F)}

Fetch dapat didefinisikan sebagai panjang pembangkit gelombang pada arah 
datangnya angin. Menurut Triatmodjo, B (2009 : 124) panjang fetch adalah panjang laut yang dibatasi oleh pulau-pulau pada kedua ujungnya. Panjang fetch membatasi waktu gelombang untuk berada dibawah pengaruh angin. Jadi, apabila fetchnya pendek, maka energi yang ditransfer angin ke air belum cukup besar, sehingga tinggi gelombang yang terjadi juga belum cukup besar. Apabila bentuk daerah pembangkit tidak teratur, maka untuk peramalan gelombang perlu ditentukan fetch efektif (Feff) dengan persamaan sebagai berikut:

$$
\text { Feff }=\frac{\sum x i^{*} \cos \alpha}{\sum \cos \alpha}
$$

Dimana :

Feff $=$ fetch efektif

$\mathrm{Xi}=$ proyeksi jarak radial pada arah angin $=$ R.cos $\alpha$

$\alpha=$ sudut antara jalur fetch yang ditinjau dengan arah angin

\section{Peramalan Tinggi Gelombang}

Setelah panjang fetch efektif didapat, maka untuk menghitung tinggi gelombang dipakai perumusan CERC, Shore Protection Manual, (1984 : 3-48) seperti yang tampak Tabel 1, dengan catatan satuan yang dipakai adalah satuan SI dengan $\mathrm{g}=9,8 \mathrm{~m} / \mathrm{s} 2$.

Tabel 1. Persamaan untuk peramalan tinggi gelombang dengan menggunakan Metode Shore Protection Manual, (1984) (satuan SI)

\begin{tabular}{|c|c|c|}
\hline \multirow[b]{2}{*}{ Dimensionless } & \multicolumn{2}{|c|}{ Metric Unit } \\
\hline & $\mathrm{H}(\mathrm{m}), \mathrm{T}(\mathrm{s}), \mathrm{UA}(\mathrm{m} / \mathrm{s}), \mathrm{F}(\mathrm{m}), \mathrm{t}(\mathrm{s})$ & $\begin{array}{l}\mathrm{H}(\mathrm{m}), \mathrm{T}(\mathrm{s}), \mathrm{UA}(\mathrm{m} / \mathrm{s}), \\
\mathrm{F}(\mathrm{km}), \mathrm{t}(\mathrm{hr})\end{array}$ \\
\hline \multicolumn{3}{|l|}{ Fetch Limited, $(\mathrm{F}, \mathrm{U})$} \\
\hline$\frac{g}{H s_{o}}=1.600 \times 10^{-3}\left(\frac{g F}{U_{A}{ }^{2}}\right)^{1}$ & $H s_{o}=5.112 \times 10^{-4} \cdot U_{A} \cdot F^{1 / 2}$ & $H s_{o}=1.616 \times\left. 10^{-2} \cdot U_{A} \cdot F^{1}\right|_{2}$ \\
\hline$\frac{g T o}{U_{A}}=2.857 \times 10^{-1}\left(\frac{g F}{U_{A}^{2}}\right)^{1}$ & $T_{o}=6.238 x 10^{-2} \cdot\left(U_{A} \cdot F\right)^{1 / 3}$ & $T_{o}=6.238 \times 10^{-1} .\left(U_{A} \cdot F\right)^{1}$ \\
\hline$\frac{g t}{U_{A}}=6.880 \times 10^{1}\left(\frac{g F}{U_{A}^{2}}\right)^{2 / 3}$ & $t=3.215 \times 10^{1}\left(\frac{F^{2}}{U_{A}}\right)^{1 / 3}$ & $t=8.930 \times 10^{-1}\left(\frac{F^{2}}{U_{A}}\right)^{1 / 3}$ \\
\hline \multicolumn{3}{|l|}{ Fully Developed Sea } \\
\hline$\frac{g H s_{o}}{U_{A}^{2}}=2.433 \times 10^{-1}$ & $H s_{o}=2.482 \times 10^{-2} \cdot U_{A}^{2}$ & $H s_{o}=2.4821 \times 10^{-2} U_{A}{ }^{2}$ \\
\hline$\frac{g T_{o}}{U_{A}}=8.134$ & $T_{o}=8.3 \times 10^{-1} \cdot U_{A}$ & $T_{o}=8.3 \times 10^{-1} \cdot U_{A}$ \\
\hline$\frac{g t}{U_{A}}=7.15 \times 10^{1}$ & $t=7.296 \times 10^{3} x U_{A}$ & $t=2.027 x U_{A}$ \\
\hline \multirow[b]{2}{*}{ Notation } & \multirow{2}{*}{$g=9.8 \mathrm{~m} / \mathrm{s}^{2}$} & $g=9.8 \mathrm{~m} / \mathrm{s}^{2}$ \\
\hline & & $\begin{array}{l}1 \text { kilometer }=1000 \mathrm{~m} \\
1 \text { hour }=3600 \mathrm{~s}\end{array}$ \\
\hline
\end{tabular}

Sumber : CERC, Shore Protection Manual, (1984 : 3-48) 


\section{Transpor Sedimen Pantai}

Transpor sedimen pantai adalah gerakan di daerah pantai yang disebabkan oleh gelombang dan arus. Transport sedimen pantai terjadi pada daerah antara gelombang pecah dan garis pantai. Sedimen transport pantai dapat diklasifisikan menjadi transpor sedimen menuju dan meninggalkan pantai (onshore-offshore sediment transport) dan sedimen transport sepanjang pantai (longshore sediment transport).

Triatmodjo, B (2009:130) menyebutkan transpor sedimen sepanjang pantai banyak menyebabkan permasalahan didalam pencegahan sedimentasi di pelabuhan dan erosi pantai, oleh karena itu prediksi transpor sedimen sepanjang pantai untuk berbagai kondisi sangat penting. Triatmodjo, B (2009:131) menyebutkan perhitungan angkutan sedimen sepanjang pantai dapat dihitung dengan rumus CERC (1984) :

$$
\mathrm{Q}_{\mathrm{s}}=1290 \mathrm{P}_{1}
$$

dimana :

$$
\begin{aligned}
\mathrm{Q}_{\mathrm{s}}= & \text { angkutan sedimen sepanjang pantai } \\
(\mathrm{m} 3 / \text { hari }) & \\
\mathrm{P}_{1}= & \text { komponen fluks energi gelombang } \\
& \text { sepanjang pantai pada saat pecah } \\
& (\mathrm{Nm} / \mathrm{d} / \mathrm{m})
\end{aligned}
$$

Pada studi ini untuk menunjukan besarnya jumlah angkutan longshore sediment digunakan perumusan CERC (1984), mengingat perumusan ini lebih sederhana dan sesuai kondisi di lapangan. Adapun syarat-syarat dalam pemakaian rumus CERC adalah :

Volume 1, No. 1, Januari 2015
- Diameter pasir antara $175 \mu \mathrm{m}-1000 \mu \mathrm{m}$ (0.175mm-1mm)

- Gaya yang bekerja pada air laut hanya berasal dari gaya gelombang.

\section{Jetty}

Jetty merupakan konstruksi penangkis gelombang yang dapat berfungsi untuk menurunkan tinggi gelombang dari laut dalam. Selain itu Jetty dapat juga digunakan untuk mengarahkan sedimen agar tidak masuk alur lalu-lintas kapal, menghindarkan arah perjalanan kapal dari pengaruh cross current dan juga dapat berfungsi sebagai tambatan untuk muatan berbahaya.

\section{Stabilisasi Batu Lapis Pelindung}

Kestabilan dari jetty rubble mound ini sangat tergantung pada berat dan bentuk material penyusun primary layer/lapisan pelindung dan juga kemiringan dasarnya.

Berat material penyusun lapisan pelindung ini dapat ditentukan menggunakan rumus hasil analisa Hudson (1953) :

$$
W=\frac{\rho_{a} H^{3}}{K_{D} * \Delta^{3} * \cot \theta}
$$

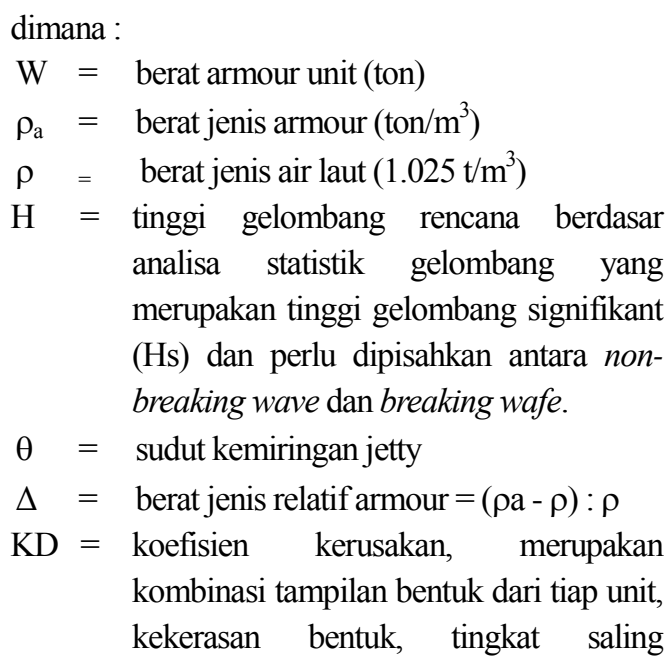
analisa statistik gelombang yang merupakan tinggi gelombang signifikant (Hs) dan perlu dipisahkan antara nonbreaking wave dan breaking wafe.

$\theta=$ sudut kemiringan jetty

$\Delta=$ berat jenis relatif armour $=(\rho a-\rho): \rho$

$\mathrm{KD}=$ koefisien kerusakan, merupakan kombinasi tampilan bentuk dari tiap unit, kekerasan bentuk, tingkat saling 
penguncian dan keadaan pecahnya gelombang.

\section{METODE PENELITIAN}

Perencanaan dimulai dengan penelitian di lapangan, pengumpulan data dan analisis data.

\section{Pengumpulan Data \\ a. Data Primer}

Data Primer adalah data yang diperlukan sebagai pendukung utama dalam analisis. Adapun data primer yang diperlukan untuk pekerjaan ini sebagai berikut:

- Pemetaan bathimetri dan topografi

- Data pasang surut

- Data arus

- Data sedimentasi

- Data geologi

- Data kapal

Data-data ini didapat melalui survei lapangan.

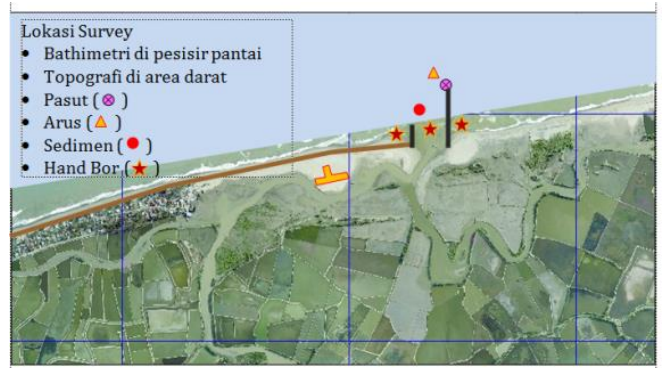

Gambar 3. Lokasi survei bathimetri, topografi, hidro-oceanografi dan geologi

\section{b. Data Sekunder}

Data sekunder adalah data pendukung dari data primer. Adapun yang termasuk data sekunder yaitu data angin. Data angin didapat dari Stasiun Meteorologi Malaikul Saleh selama 16 tahun (1989-2004). Data ini dipakai untuk memprediksikan tinggi gelombang dan fetch efektif yang terjadi.

\section{Analisis Data}

Setelah data-data lapangan diperoleh, kemudian dilanjutkan dengan melakukan analisis bathimetri dan topografi, pasang surut, arus, gelombang, sedimentasi dan geologi.

\section{Penanganan}

Rencana penanganan diberikan terhadap penentuan lay out jetty, lebar dan kedalaman alur pelayaran, kolam putar dan desain typical konstruksi jetty. Disamping itu perlu diperkirakan total volume pengerukan.

\section{HASIL PEMBAHASAN}

\section{Bathimetri dan topografi}

Berdasarkan hasil survei bathimetri seluas $1.5 \mathrm{~km}^{2}$, dapat disimpulkan bahwa perairan di pantai Kuala Raja tergolong landai dengan kedalaman -5.00 mLWS pada jarak $300 \mathrm{~m}$ dari garis pantai. Sementara dari hasil pengukuran lahan seluas $\pm 50 \mathrm{Ha}$ menunjukan bahwa topografi di lokasi studi relaif datar dengan tinggi elevasi 0 sampai $3 \mathrm{~m}$.

\section{Pasang Surut}

Pasang surut yang terjadi di perairan Kuala Raja adalah tipe pasang surut campuran condong ke harian ganda yaitu yaitu dalam satu hari terjadi dua kali pasang dan dua kali surut tetapi tinggi dan periodenya berbeda. Beda muka air pasang surut sebesar $1.56 \mathrm{~m}$ di atas posisi $0.0 \mathrm{~m}$ LWS. Adapun kedudukan airnya adalah 
sebagai berikut:

HWS $=156 \mathrm{~cm}$ diatas LWS atau $211 \mathrm{~cm}$ dari pembacaan piel scale

MLS $=78 \mathrm{~cm}$ diatas LWS atau $133 \mathrm{~cm}$ dari piel scale

LWS $=0.00 \mathrm{~cm}$ atau $55 \mathrm{~cm}$ dari pembacaan piel scale

\section{Arus}

Dari data diketahui kecepatan arus sangat kecil, yaitu kurang dari $1.5 \mathrm{~m} /$ detik kondisi tersebut tidak mengganggu pergerakan (manuver) kapal. Karena kapal yang melintasi alur pelayaran direncanakan ukuranya kurang dari 50 GT. Jadi kondisi arus di pantai Kuala Raja belum menyulitkan pergerakan kapal.

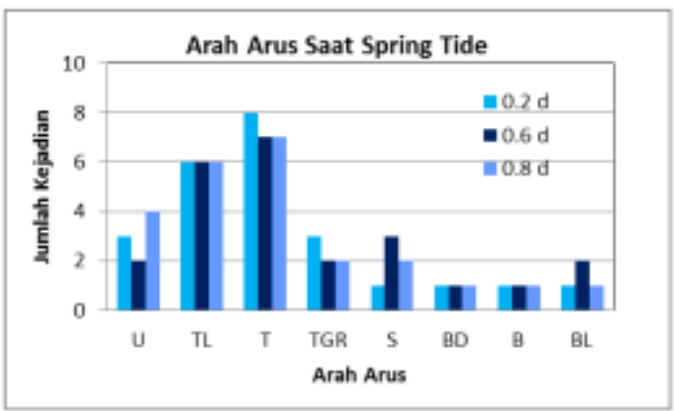

Gambar 4. Arah Arus Dominan saat Spring Tide

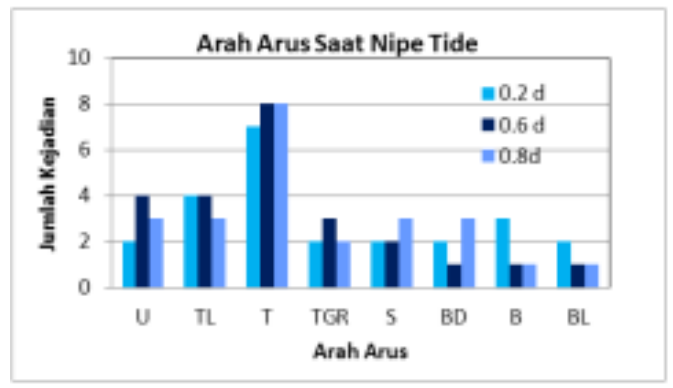

Gambar 5. Arah Arus Dominan Saat Nipe Tide

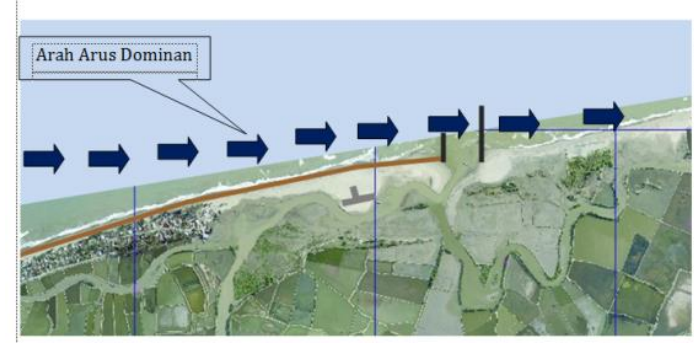

\section{Gambar 6. Arah Arus Dominan Pantai} Kuala Raja

\section{Gelombang}

Rata-rata angin bertiup dari arah Timur dan Timur Laut dengan kecepatan $>5$ knot sebesar 12,27-13,71 \%. Persentase kejadian angin dengan kecepatan maksimum juga terjadi pada saat angin bertiup dari arah Timur Laut, Timur dan Tenggara. Persentase kejadian angin maksimum ( $>10$ knot) adalah 2,64-4,61\%. Untuk lebih jelasnya dapat dilihat pada gambar berikut ini.

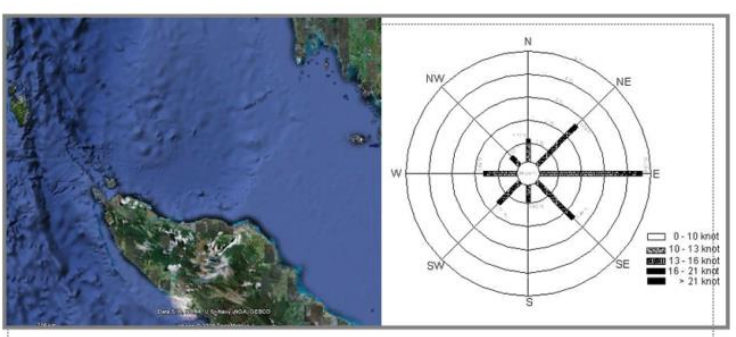

Gambar 7. Mawar Angin dari Persentase Kejadian Angin Maksimum Periode 1989-2004

\section{Fetch Efektif}

Berdasarkan hasil perhitungan fetch, (Tabel 2 dan Gambar 8), dapat diketahui bahwa pada lokasi Pantai Kuala Raja, fetch terpanjang adalah arah Utara yang mencapai $490.04 \mathrm{~km}$

Perhitungan tinggi gelombang di laut dalam dapat dilihat pada Tabel 3 dan Tabel 4 berikut ini. 


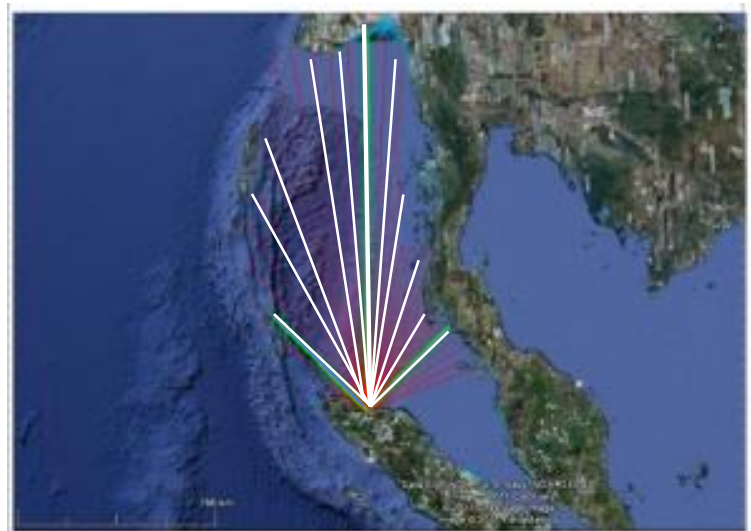

Berdasarkan hasil perhitungan pada Tabel 3 dan Tabel 4, dapat dilihat, tingggi gelombang terbesar terjadi pada keadaan fully developed sea yaitu sebesar 3,87 m sementara periode yang terjadi adalah 10,36 dengan waktu 25,31 detik, kejadian tersebut terjadi pada kecepatan angin $>20$ knot dengan frekuensi kejadian sangat kecil yaitu 8,58 \%.

\section{Gambar 8. Fetch Efektif}

Tabel 2 Perhitungan fetch efektif di perairan Pantai Kuala Raja

\begin{tabular}{|c|c|c|c|c|c|c|c|}
\hline \multirow{2}{*}{$\alpha$} & \multirow{2}{*}{$\cos \alpha$} & BL & $\mathbf{U}$ & TL & BL & $\mathbf{U}$ & TL \\
\hline & & xi (km) & xi (km) & xi (km) & $\mathrm{xi} \cos \alpha$ & $\mathrm{xi} \cos \alpha$ & $\mathrm{xi} \cos \alpha$ \\
\hline 42 & 0,74314 & 0 & 500 & 500 & 0.00 & 371.57 & 371.57 \\
\hline 36 & 0,80902 & 18 & 500 & 500 & 14.56 & 404.51 & 404.51 \\
\hline 30 & 0,86603 & 24 & 500 & 500 & 20.78 & 433.01 & 433.01 \\
\hline 24 & 0,91355 & 69 & 500 & 500 & 63.03 & 456.77 & 456.77 \\
\hline 18 & 0,95106 & 158 & 500 & 484 & 150.27 & 475.53 & 460.31 \\
\hline 12 & 0,97815 & 172 & 500 & 423 & 168.24 & 489.07 & 413.76 \\
\hline 6 & 0,99452 & 414 & 500 & 451 & 411.73 & 497.26 & 448.53 \\
\hline 0 & 1 & 500 & 500 & 457 & 500.00 & 500.00 & 457.00 \\
\hline 6 & 0,99452 & 500 & 500 & 437 & 497.26 & 497.26 & 434.61 \\
\hline 12 & 0,97815 & 500 & 500 & 468 & 489.07 & 489.07 & 457.77 \\
\hline 18 & 0,95106 & 500 & 500 & 395 & 475.53 & 475.53 & 375.67 \\
\hline 24 & 0,91355 & 500 & 500 & 451 & 456.77 & 456.77 & 412.01 \\
\hline 30 & 0,86603 & 500 & 458 & 32 & 433.01 & 396.64 & 27.71 \\
\hline 36 & 0,80902 & 500 & 420 & 0 & 404.51 & 339.79 & 0.00 \\
\hline 42 & 0,74314 & 500 & 455 & 0 & 371.57 & 338.13 & 0.00 \\
\hline Total & 13,5109 & & & & 4456.35 & 6620.92 & 5153.23 \\
\hline & & Feff $(\mathrm{km})$ & & & 329.83 & 490.04 & 381.41 \\
\hline
\end{tabular}

Tabel 3. Perhitungan tinggi gelombang laut dalam berdasarkan fetch limited

\begin{tabular}{|c|c|c|c|c|c|c|c|c|c|c|c|c|c|c|}
\hline \multirow{2}{*}{$\begin{array}{l}\text { KEC. } \\
\text { ANGIN } \\
\text { (Knot) }\end{array}$} & \multirow{2}{*}{$\begin{array}{c}\mathrm{U}_{\mathrm{L}} \\
(\mathrm{m} / \mathrm{dt})\end{array}$} & \multirow{2}{*}{$\begin{array}{c}\text { UA } \\
\text { (m/dt) }\end{array}$} & \multicolumn{3}{|c|}{ Fetch $(\mathrm{km})$} & \multicolumn{3}{|c|}{ Hso } & \multicolumn{3}{|c|}{ To } & \multicolumn{3}{|c|}{$\mathrm{t}$} \\
\hline & & & $\mathrm{BL}$ & $\mathrm{U}$ & $\mathrm{TL}$ & $\mathrm{BL}$ & $\mathrm{U}$ & $\mathrm{TL}$ & BL & $\mathrm{U}$ & $\mathrm{TL}$ & $\mathrm{BL}$ & $\mathrm{U}$ & $\mathrm{TL}$ \\
\hline$<10$ & 5,14 & 5,32 & 329.83 & 490.04 & 381.41 & 1.56 & 1.90 & 1.68 & 7.53 & 8.59 & 7.90 & 24.42 & 31.79 & 26.90 \\
\hline $10-13$ & 5,92 & 6,32 & 329.83 & 490.04 & 381.41 & 1.86 & 2.26 & 2.00 & 7.97 & 9.09 & 8.36 & 23.06 & 30.02 & 25.40 \\
\hline $13-16$ & 7,46 & 8,41 & 329.83 & 490.04 & 381.41 & 2.47 & 3.01 & 2.65 & 8.76 & 10.00 & 9.20 & 20.97 & 27.30 & 23.10 \\
\hline $16-20$ & 9,26 & 10,97 & 329.83 & 490.04 & 381.41 & 3.22 & 3.92 & 3.46 & 9.58 & 10.93 & 10.05 & 19.19 & 24.98 & 21.14 \\
\hline$>20$ & 10,29 & 12,49 & 329.83 & 490.04 & 381.41 & 3.66 & 4.47 & 3.94 & 10.00 & 11.41 & 10.50 & 18.38 & 23.93 & 20.24 \\
\hline
\end{tabular}

Tabel 4. Koreksi tinggi gelombang berdasarkan keadaan fully developed sea

\begin{tabular}{|c|c|c|c|c|c|c|c|c|c|c|c|c|c|c|}
\hline \multirow{2}{*}{$\begin{array}{l}\text { KEC. } \\
\text { ANGIN } \\
\text { (Knot) }\end{array}$} & \multirow{2}{*}{$\begin{array}{c}\mathrm{U}_{\mathrm{L}} \\
(\mathrm{m} / \mathrm{dt})\end{array}$} & \multirow{2}{*}{$\begin{array}{c}\mathrm{UA} \\
(\mathrm{m} / \mathrm{dt})\end{array}$} & \multicolumn{3}{|c|}{ Fetch $(\mathrm{km})$} & \multicolumn{3}{|c|}{ Hso } & \multicolumn{3}{|c|}{ To } & \multicolumn{3}{|c|}{$t$} \\
\hline & & & $\mathrm{BL}$ & $\mathrm{U}$ & $\mathrm{TL}$ & $\mathrm{BL}$ & $\mathrm{U}$ & $\mathrm{TL}$ & $\mathrm{BL}$ & $\mathrm{U}$ & $\mathrm{TL}$ & $\mathrm{BL}$ & $\mathrm{U}$ & $\mathrm{TL}$ \\
\hline$<10$ & 5,14 & 5,32 & 329.83 & 490.04 & 381.41 & 0.70 & 0.70 & 0.70 & 4.42 & 4.42 & 4.42 & 10.79 & 10.79 & 10.79 \\
\hline $10-13$ & 5,92 & 6,32 & 329.83 & 490.04 & 381.41 & 0.99 & 0.99 & 0.99 & 5.25 & 5.25 & 5.25 & 12.81 & 12.81 & 12.81 \\
\hline $13-16$ & 7,46 & 8,41 & 329.83 & 490.04 & 381.41 & 1.75 & 1.75 & 1.75 & 6.98 & 6.98 & 6.98 & 17.04 & 17.04 & 17.04 \\
\hline $16-20$ & 9,26 & 10,97 & 329.83 & 490.04 & 381.41 & 2.99 & 2.99 & 2.99 & 9.10 & 9.10 & 9.10 & 22.23 & 22.23 & 22.23 \\
\hline$=20$ & 10,29 & 12,49 & 329.83 & 490.04 & 381.41 & 3.87 & 3.87 & 3.87 & 10.36 & 10.36 & 10.36 & 25.31 & 25.31 & 25.31 \\
\hline
\end{tabular}


Sementara berdasarkan koreksi menggunakan nomogram dari SPM diperoleh tinggi gelombang $3,50 \mathrm{~m}$ dengan periode 8 detik dengan durasi minimum 11 jam untuk tegangan angin dengan kecepatan $>20$ knot dengan fetch terbesar arah Utara sebesar 490,04 Km.

\section{Transpor sedimen pantai}

Berdasarkan analisa transpor sedimen menunjukan bahwa terjadi sedimentasi ke arah Timur sebesar 46.934,59 $\mathrm{m}^{3} /$ tahun. Hal ini sesuai dengan kondisi di lapangan dimana pada pantai di sisi kiri bangunan jetty yang ada sekarang sedimen lebih tebal daripada sisi kanan jetty. Pada Gambar 9 disajikan alur transpor sedimen di Pantai Kuala Raja.

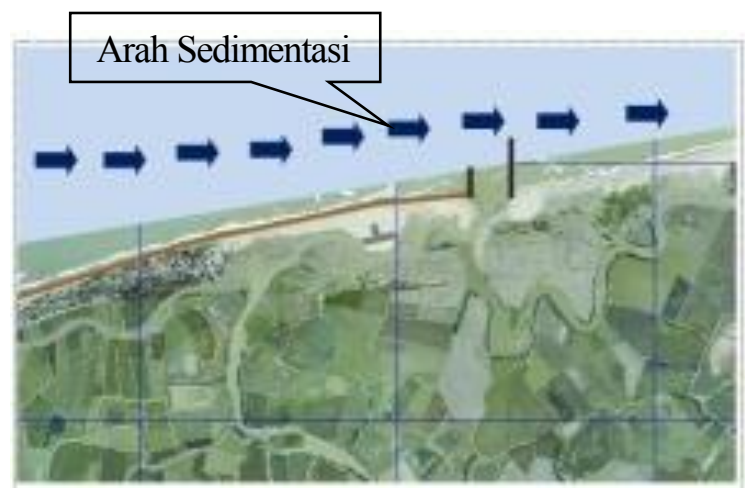

Gambar 9. Arah Sedimentasi di Perairan Pantai Kuala Raja

\section{Penyelidkan Tanah}

Dari data handbor pada lokasi rencana penambahan jetty, didapat $\mathrm{SG}=2.648$, $\mathrm{Wc}=25.66, \gamma \mathrm{d}=1.549, \phi=31.00, \mathrm{c}=0.03$

\section{Layout}

Bangunan Jetty yang ada saat ini berupa jetty pendek tidak mampu menghambat laju

Volume 1, No. 1, Januari 2015 sedimen yang masuk pada alur pelayaran. Untuk menghambat laju sedimen maka jetty perlu diperpanjang sampai pada kedalaman gelombang pecah. Kedalaman gelombang pecah di pantai Kuala Raja mencapai $-4,00$ mLWS. Dengan mempertimbangkan datadata yang ada dan kedalaman laut maka jetty di pantai Kuala Raja perlu diperpanjang 284 m pada sisi kiri dan 127,65 m pada sisi kanan jetty dengan kedalaman sampai dengan $-5,0$ mLWS (Gambar 10).

\section{Alur Pelayaran}

Untuk mendapatkan kedalaman alur nominal maka direncanakan kedalaman air di Pelabuhan Kuala Raja dengan mempertimbangkan faktor-faktor yang yang mempengaruhi pengerukan kedalaman alur. Kedalaman air total adalah :

$$
\begin{aligned}
& H=d+R+P+K \\
& H=1.50+0.5+0.5+0.5 \\
& H=3.00 m
\end{aligned}
$$

dimana :

$\mathrm{d}=$ draft kapal

$\mathrm{R} \quad=$ ruang kebebasan bersih

$\mathrm{P} \quad=$ ketelitian pengukuran

$\mathrm{K}=$ toleransi pengukuran

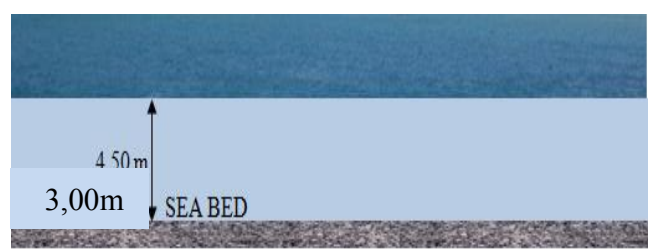

Gambar 11. Kedalaman alur pelayaran

\section{Jetty}

Berdasarkan perhitungan didapat berat armour unit pada masing-masing lapisan seperti pada Tabel 5 berikut ini. 


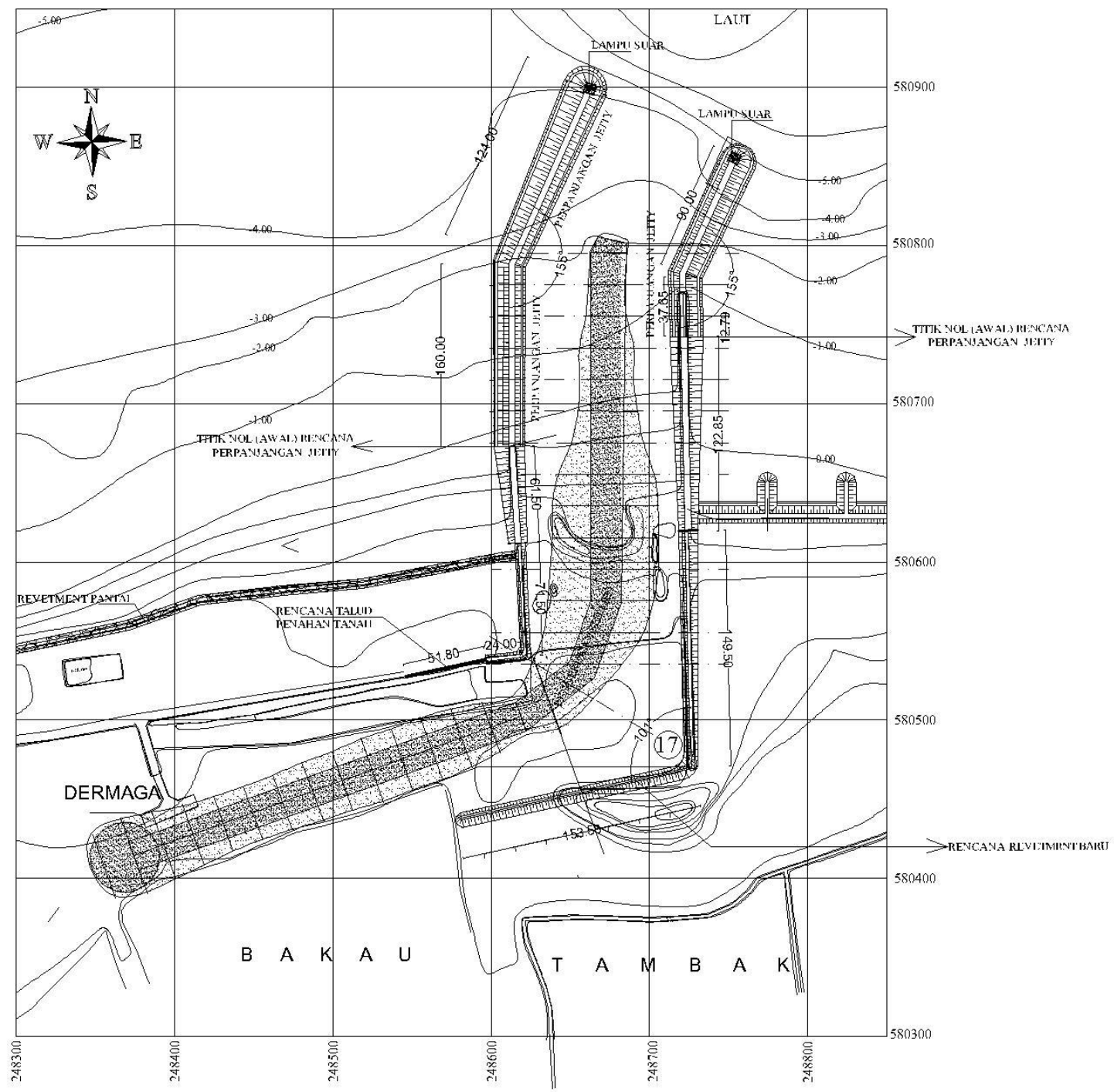

Gambar 10. Layout desain jetty pantai kuala raja

Tabel 5 Berat armour unit pada masingmasing layer

\begin{tabular}{|c|c|c|c|c|}
\hline \multirow{2}{*}{$\begin{array}{c}\text { Bangunan } \\
\text { Pantai }\end{array}$} & $\begin{array}{c}\text { Primer } \\
\text { Layer }\end{array}$ & $\begin{array}{c}\text { Secondary } \\
\text { Layer }\end{array}$ & $\begin{array}{c}\text { Core } \\
\text { Layer }\end{array}$ & Berm \\
\cline { 2 - 5 } & $\begin{array}{c}\mathrm{Wp} \\
\text { (ton) }\end{array}$ & $\mathrm{Wp}(\mathrm{kg})$ & $\begin{array}{c}\mathrm{Wp} \\
(\mathrm{kg})\end{array}$ & $\begin{array}{c}\mathrm{Wp} \\
(\mathrm{kg})\end{array}$ \\
\hline Jetty & 2.5 & $150-250$ & $0.5-10$ & $150-250$ \\
\hline
\end{tabular}

Tabel 6. Tebal Lapisan pada MasingMasing Layer

\begin{tabular}{|c|c|c|c|c|}
\hline $\begin{array}{c}\text { Bangunan } \\
\text { Pantai }\end{array}$ & $\begin{array}{c}\text { Koef. } \\
\text { Porositas } \\
(\%)\end{array}$ & $\begin{array}{c}\text { t Lap } \\
\text { Primer } \\
(\mathrm{m})\end{array}$ & $\begin{array}{c}\text { t Lap } \\
\text { Sekunder } \\
(\mathrm{m})\end{array}$ & $\begin{array}{c}\text { t Lap } \\
\text { Berm } \\
(\mathrm{m})\end{array}$ \\
\hline Jetty & 37 & 2.30 & 1.60 & 1.60 \\
\hline
\end{tabular}

\section{Pengerukan}

Pengerukan dilakukan pada alur pelayaran di muara pantai Kuala Raja. Berdasarkan hasil analisa diketahui bahwa kedalaman alur pelayaran yang diperlukan $-3.00 \mathrm{mLWS}$ dan lebar $19 \mathrm{~m}$.

Perhitungan volume jumlah pengerukan didasarkan pada gambar cross section dan long section. Dari rekapitulasi perhitungan volume pengerukan terlihat bahwa volume pengerukan total adalah $39.811,60 \mathrm{~m}^{3}$. 


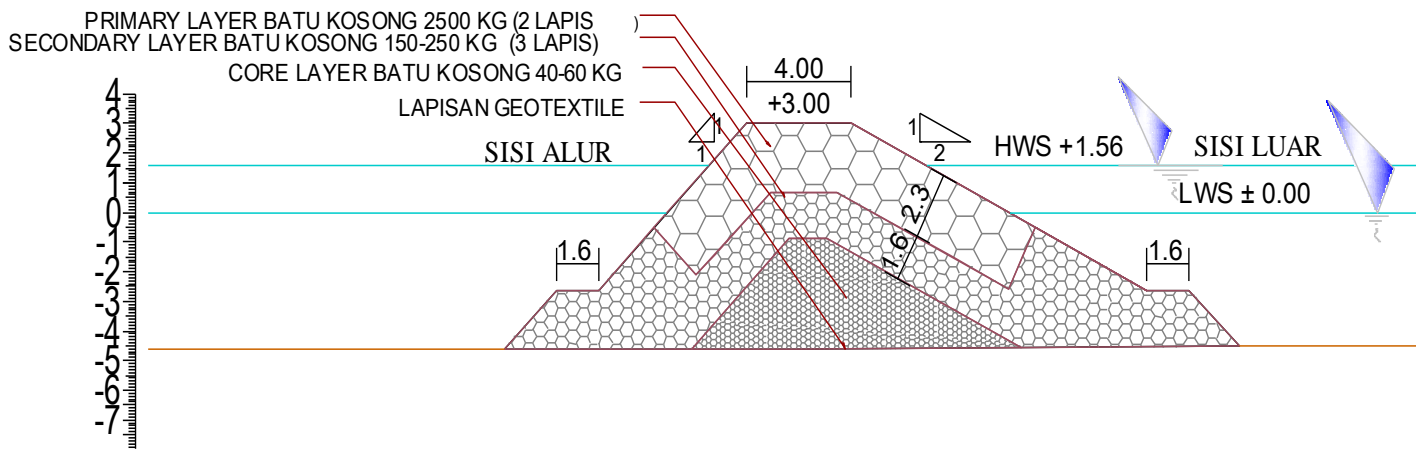

Gambar 12. Typical Konstruksi Jetty

\section{KESIMPULAN DAN SARAN}

\section{Kesimpulan}

Kesimpulan yang dapat diambil dari studi yang telah dilakukan ini adalah :

1. Topografi pelabuhan Kuala Raja relatif datar dengan elevasi 0 sampai 3 meter. Berdasarkan survei bathimetri seluas 1,5 $\mathrm{Km}^{2}$, dapat disimpulkan bahwa pantai Kuala Raja tergolong landai dengan kedalaman -5.00 mLWS pada jarak 300 meter dari garis pantai.

2. Jenis pasang surut yang terjadi di Pelabuhan Kuala Raja adalah tipe pasang surut campuran yaitu dalam satu hari terjadi dua kali pasang dan dua kali surut tetapi tinggi dan periodenya berbeda. Beda muka air pasang surut sebesar 156 $\mathrm{cm}$ di atas posisi $0.00 \mathrm{~m}$ LWS.

3. Kecepatan arus yang terjadi sangat kecil yaitu kurang dari $1.5 \mathrm{~m} /$ detik, kondisi ini tidak mengganggu pergerakan kapal.

4. Pergerakan sedimen transport di pantai Kuala Raja terjadi sebesar $\pm 46.934,59$ $\mathrm{m}^{3} /$ tahun yang bergerak dari arah Barat ke Timur. Hal ini terlihat jelas pada tumpukan sedimen yang terjadi pada sisi kiri jetty.

5. Berdasarkan pertimbangan teknis dan ekonomis maka desain jetty dibuat mengarah ke Arah Timur Laut. Konstruksi jetty di lokasi muara pantai Kuala Raja mempunyai panjang keseluruhan $349 \mathrm{~m}$ yang terdiri dari sisi kiri $284 \mathrm{~m}$ (bangun baru) dan sisi kanan 127,65 (bangun baru). Ujung jetty yang terdalam terletak pada perairan dengan kedalaman $-5 \mathrm{~m}$ LWS. Puncak jetty pada ketinggian $+3.00 \mathrm{~m}$ LWS, dengan lebar puncak jetty $4 \mathrm{~m}$ di kepala jetty. Kemiringan jetty pada sisi laut $1: 2$ dan sisi alur adalah $1: 1$. Jetty terdiri dari beberapa lapisan dengan berat Armour Unit masing-masing yaitu: primer layer (2.5 ton), secondary layer (150-250 kg), core layer $(0.5-10 \mathrm{~kg})$ dan berm (150-250 $\mathrm{kg})$.

6. Untuk menampung kapal dalam melakukan berth time (waktu sandar) maka disediakan kolam pelabuhan dengan kedalaman 3 meter dan panjang kolam putar 22.5 meter. 
7. Total volume pengerukan adalah sebesar $\pm 39.811,60 \mathrm{~m}^{3}$. Tipe kapal keruk yang sesuai untuk kondisi pengerukan di pantai Kuala Raja adalah Backhoe dredger yang merupakan ponton yang dipasang alat pemindah tanah berupa backhoe.

\section{Saran}

a. Perlu dilakukan rekayasa teknis secara menyeluruh mengenai penanggulangan kerusakan pantai, prasarana dan sarana serta permukiman.

b. Perlu dilakukan kajian pengelolaan kawasan pantai yang berkesinambungan dengan adanya perencanaan dan pembangunan wilayah pesisir.

\section{DAFTAR PUSTAKA}

Triatmodjo, Bambang, 2009. Perencanaan Pelabuhan, Beta Offset, Yogyakarta

CERC, 1984, Shore Protection Manual Volume I, US Army Coastal Engineering Research Center, Washington.

Silvester, Richard, 1974, Coastal Engineering 1, University of Western Australia, Nedland.

Yuwono, Nur. Ir.Dipl.HE., 1982, Teknik Pantai Volume 1, Biro Penerbit KMTS Fak. Teknik UGM, Yogyakarta.

Kramadibrata Soejono, 2001, Perencanaan Pelabuhan, ITB, Bandung 